This is the peer reviewed version of the following article: Bossavit, B, Parsons, S. Outcomes for design and learning when teenagers with autism codesign a serious game: A pilot study. J Comput Assist Learn. 2018; 34: 293- 305, which has been published in final form at https://doi.org/10.1111/jcal.12242. This article may be used for non-commercial purpqses in accordance with Wiley Terms and Conditions for Use of Self-Archived Versions.

Accepted for publication, Journal of Computer Assisted Learning, $10^{\text {th }}$ January 2018

\title{
Outcomes for Design and Learning when Teenagers with Autism Co-Design a Serious Game: a pilot study
}

Benoît Bossavit \& Sarah Parsons

\begin{abstract}
Digital educational games research tends to lack ecological validity by not adequately taking into account the views and perspectives of children and young people with autism spectrum disorders (ASD). In technology applications for autism there is also a focus mostly on learning of social communication rather than academic subjects. This paper is a pilot study that explores the potential of including the views and perspectives of people with autism by analysing an academic-based educational game that was co-designed with and for young people with ASD. The serious game aims to help the players learn Geography-specific knowledge and integrates several strategic features so that users can collaborate together against the computer or compete against each other. The educational game was evaluated over five sessions by three peer teams from two different special educational institutions, involving a total of six students with ASD. The participants were positive about their enjoyment and motivation as well as social engagement. The results showed that the players' level of competitiveness not only influenced the experience within the game but also the interaction within the peer teams. The game mechanisms did help the participants with ASD increase their knowledge in Geography content. The main conclusion is that there are considerable benefits of including children with ASD in the design process and future research should explore more fully how their involvement can enhance curriculum-based learning as well as social engagement within the classroom.
\end{abstract}

\section{Keywords}

Educational game; Academic Content; Autism; User centred design 


\section{Introduction}

Autism Spectrum Disorder (ASD) is characterized by impairments in the core areas of social communication and interaction, coupled with repetitive and stereotypical behaviours (American Psychiatric Association, 2013). There are significant social and economic impacts for individuals with ASD and their families (e.g. Montes \& Halterman, 2008), as well as wider economic impacts for society in providing appropriately specialist and tailored services and support (Lavelle et al., 2014). Consequently, research for children with ASD has focused on evaluating different ways in which learning support can be provided effectively, with interactive technologies playing a potentially important role (Grynszpan et al., 2014). In general, computer-based interventions for children with ASD show some positive results for supporting social communication (Bernardini et al., 2014, Serret et al., 2014) and social interaction skills (Malinverni et al., 2016; Parsons et al., 2011). However, little technologybased research has addressed academic skills and knowledge for children with ASD (Knight et al, 2013), especially beyond considerations of English and literacy (Pennington, 2010), thereby making this an area worthy of further investigation.

In this context, 'serious games' offer one type of approach that could be beneficial for supporting learning of academic content. 'Serious games' is a general term used to describe interactive technologies that are developed to support educational objectives through utilising the motivational and engaging features of digital gaming (De Freitas, 2006). Such features include the use of storyline, goals directed around targeted skills, feedback, and rewards (Whyte

et al., 2015). Research suggests that not only do serious games provide engagement and motivation with tasks, but they also offer a controlled and non-threatening environment, which might promote the acquisition of new skills, at least for children without ASD (Kapp, 2012; Molins-Ruano et al., 2014; Wrzesien \& Raya, 2010). In addition, serious games integrated in 
mainstream (general) schools have demonstrated positive effects on learning when used as a tool to support more traditional teaching methods (Annetta et al., 2009; Backlund \& Hendrix, 2013).

More broadly, there is strong emergent evidence of positive learning outcomes supported by the use of digital games for school-aged children and adolescents. In a meta-analysis of research on serious games from the last two decades, Clark et al. (2016) compared the learning outcomes of non-game conditions ('classroom as normal' or traditional instruction) versus digital game conditions in the learning process. Overall, the findings showed that students who engaged with digital games demonstrated significant benefits for learning compared to those in non-game control conditions. The meta-analysis also considered the features of digital games that may be more beneficial for learning for example, offering several possibilities for actions within the game, and providing direct feedback after a success or a failure (Clark et al., 2016). Overall, increased contextualisation of the game, including greater anthropomorphism, the use of more realistic images, and a relevant story narrative, correlated with smaller effects on learning outcomes. This suggests that there may not be substantial advantages to overly complicating the game and the graphics.

However, there is a lack of evidence that demonstrates the generalization of the learned skills or knowledge from serious games to real life (Girard et al., 2013; Whyte et al., 2015). Additionally, Granic et al. (2014) highlight that most research in this area has taken place with 'single-user' games [where players play the game against the computer] rather than considering the dual or multi-player games that most children and young people play with their friends. Therefore, existing research in digital games strongly lacks ecological validity (Granic et al., 2014). Problems with validity also extend to the design of the games since "...medical practitioners, teachers, and researchers are not game designers, and as a result, they often 
develop products that miss the most essential mechanism of engagement in games - the fun" (Granic et al., 2014; p.74). Consequently, there is a strong argument for the importance of usercentred design processes that involve children and young people directly in order to better understand how fun can be included in the development of serious games. Indeed, teenagers are probably the most experienced designers since this is an age when many may spend a lot of time playing video games (Durkin et al., 2013).

There is a further issue related to validity of the serious games evidence base in relation to children with ASD. While there is general strong support for the use of digital games for supporting learning from Clark et al., (2016), the participants were all typically developing and so it is not yet clear to what extent these findings may relate to children and adolescents with ASD. This difference is important because children and young people with ASD often require special attention for supporting learning, taking into account the core areas of difficulty characterized by the ASD diagnosis (Ploog et al., 2013; Wass \& Porayska-Pomsta, 2014). Consequently, teaching and learning activities should be shaped to accommodate children's learning preferences, needs, and skills (Jordan, 2005). This is not an easy or straightforward process because this requires a good understanding of autism, as Ravet (2011, p.676) argues:

'Teachers who do not understand the diagnosis of autism, or appreciate its import, will find it difficult to anticipate, recognise, understand and address the degree of distortion of development they are dealing with when confronted with a child on the spectrum'.

Moreover, much of the research into serious games and autism tends to focus on learning related to the social and communication difficulties at the core of the diagnosis (Wass \& PorayskaPomsta, 2014). While social communication is a very important area of learning for children with ASD, this research focus neglects the important question of learning more broadly. Indeed, 
there is a lack of quality studies that focus on complex academic skills and knowledge (Knight et al., 2013).

Therefore, we aimed to conduct a small-scale pilot study to target some of the specific gaps identified in the literature viz. (1) much of the serious games literature does not include children with ASD; (2) the digital games literature related to ASD tends to focus on learning of social communication rather than academic subjects; and (3) digital games research in general tends to lack ecological validity by not adequately taking into account the views and perspectives of children and young people. Specifically, we involved high-functioning teenagers with ASD in the design process of a serious game based on learning about specific countries and their geographical locations and characteristics. Below, we first briefly describe the development of the game and then report its evaluation by adolescents with ASD who were not involved in its creation. This study aims to determine whether such a co-designed game would be acceptable and usable for other students for whom it was designed regarding their engagement, social behaviours, enjoyment and motivation, as well as the learning of Geography-specific knowledge. Furthermore, this paper also provides insights into the positive impact of involving children with ASD in the game creation via a Participatory (learner-centred) Design approach as well as some recommendation for further research in this area.

\section{Serious Game}

We implemented a participatory, learner-centred design approach via the 3T 'sandwich model' proposed by Parsons and Cobb (2014; Parsons, 2015). The model is described as a sandwich because only if the layers are appropriately integrated and aligned can a good 'sandwich' (or, in this case, educational design prototype) be produced (Parsons \& Cobb, 2014). According to the model, the top slice represents the top-down Theories that are used to develop and inform 
the educational tasks i.e. the knowledge and concepts that are derived from research evidence from different academic disciplines as well as understanding of appropriate pedagogy. Ravet's (2011) argument about the need to understand learning through the lens of ASD is especially relevant to this layer of the sandwich. In addition, we utilised pedagogic features of gamification that are known to support children's learning such as in-game rewards and scoring (Whyte et al., 2015). Gamification refers to 'the use of game design elements in non-game contexts' (Deterding et al., 2011).

It was also important to consider the mode of play and how that might support learning. Clark et al. (2016) found that competition was an important factor in promoting learning gains for typically developing children. Granic et al. (2014) demonstrated that digital games specifically supporting cooperative behaviours can improve prosocial behaviours both within and beyond game contexts. Parsons (2015) argues that supporting cooperative behaviours in children with ASD 'by stealth' via collaborative technologies can be an effective way of supporting engagement and learning. Consequently, the stakeholders in the present project were empowered to decide the content of the game but with the stipulation of designing at least two modes: a competition mode and a cooperative one. Depending on the personality of the users, one mode could fit better than the other and thus provide a better learning experience.

The middle part of the sandwich model - the 'filling' - represents the specific affordances of the Technology for supporting learning and interaction. We decided to use the Microsoft Kinect since it is inexpensive, compact and easy to use; all of which are important criteria for planning technology use in schools. Additionally, involving the body as the main mode of interaction with digital content has the potential to support learning through 'hands-on' or kinaesthetic experiences (Latham \& Stockman, 2014). Consequently, we decided to make the body the main element of interaction by using a Body Menu (BM) developed for the Kinect (Bossavit et al., 
2014). The Body Menu uses the advantages of proprioception through the user interacting with the software by touching specific parts of the body such as shoulders or head.

Finally, the bottom slice of the model defines the contexts or Territories of use with the targeted users (young people with ASD), including their views and experiences as well as other stakeholders (e.g. teachers). This project was motivated by the integration of the outcomes within a school context and so it was vital to establish user- and context-specific needs. Participatory Design (PD) approaches show that by involving directly children and adults within the design process (Benton \& Johnson, 2015) their voice can be heard over time and across several sessions via the use of structured methods and materials (Benton et al., 2012, Davis et al., 2010, Frauenberger et al. 2013, Millen et al., 2011). Consequently, teachers and pupils with ASD were involved in the design of the serious game from the beginning of the project (Parsons and Cobb, 2014).

The design and development of the serious game was performed with a designer-team, which was composed of students with high functioning ASD (four males aged 11 to 15 years old). The preliminary validation of the game was performed by the tester-team, which was composed of students with high functioning autism (two male and one female teenagers aged 15 years) from a second school.

The game is a turn-taking one where users aim to win a new country by answering a question related to that country (see Figure 1). The questions are classified by categories and are selected randomly (e.g. people, rivers...). Some features inspired from tactical board games were added with the possibility of playing special power cards such as removing half of the possible answers of the following question to make it easier to answer. There are two modes: the competition mode in which a player aims at obtaining more countries than the other player, and the cooperative mode in which the two players belong to the same team and play against the 
computer, referred as NPC (Non-Player Character). For both modes, players can either play with the Body Menu where the actions are associated to parts of the body or with the mouse by clicking on the buttons displayed on the screen.

$$
\text { ***Include Figure } 1 \text { about here*** }
$$

For further details about the design methodology, challenges and the game, please see Bossavit $\&$ Parsons (2016). This paper focuses on evaluating the use of the serious game by teenagers with ASD, as well as whether specific knowledge-related learning outcomes were supported.

\section{Methodology}

\subsection{Participants}

This project involved collaboration with two specialist providers of education in the UK. The first institution was a special school for children with special educational needs, including dedicated provision for children with ASD. The second was an independent residential and educational provider offering places to students who have been highly marginalized from education for a range of reasons. There was a high proportion of children with an ASD diagnosis at this school. This second school was also involved in the serious game design process.

Initially, six students with high functioning ASD agreed to participate and were grouped into three teams of two, by the teachers (see Table 1).

***Include Table 1 about here ${ }^{* * *}$ 
$\mathrm{R} 1$ and $\mathrm{R} 2$ replaced $\mathrm{P} 2$ and $\mathrm{P} 4$ respectively when they could not participate for personal reasons. The third team decided not to continue their involvement in the middle of the introduction session because they found the game too difficult. Before the study, the students and their parents / carers were provided with a consent form which explained the project and how the sessions were organised. Moreover, they were advised that they could withdraw at any time during the evaluation. Young people could only participate if we received completed consent forms from parents / carers and if the students also agreed to take part via an assent process, which involved explaining the project and its aims in a less detailed way. The project was reviewed and approved by an ethics committee at the second author's institution (Ref\# 11661).

\subsection{Procedure}

The co-designed game includes two interaction techniques (Body Menu and mouse) and two modes (competition and cooperation). As a result, participants were grouped in pairs for the evaluation sessions because they needed to play with or against each other to complete the game successfully. The sessions took place at the schools during their timetabled ICT class. When participants used the version with the Kinect and the Body Menu, they were placed at about 2 meters from the wall where the game was projected (see Figure 2). When participants used the mouse, they played directly on a laptop.

\footnotetext{
*** Include Figure 2 about here***
}

We organized five sessions about 30 minutes each, sometimes more if the participants wanted to keep playing. The first session consisted of an introduction to the game rules and the use of the Body Menu. The other four sessions were planned to play both modes (competition and cooperation) with both user interfaces (Body Menu and mouse) alternatively (Table 2). 
***Include Table 2 about here***

\subsection{Measures and analysis}

Granic et al., (2014) describe the main domains in which digital games can have positive benefits on players: cognitive, motivational, emotional, and social. In addition, they also note the potential of digital games in the field of education for supporting specific learning outcomes; this use, of course, is strongly supported by the meta-analysis of Clark et al (2016) discussed earlier. In relation to the latter, we were particularly interested in whether children learned Geography-specific knowledge through their use of the game and we so included a knowledgebased pre- and post- test Geography quiz as one of the measures. More broadly, and in relation to the categories discussed by Granic et al., (2014) we were interested in students' engagement with and enjoyment of the game, as well as how the different modes (competition and cooperation) influenced the students' social behaviours. Therefore, we also included measures that addressed motivational, emotional, and social aspects of using the game.

\subsubsection{Engagement and social behaviours}

We looked at engagement and social interaction of the students towards the software. In terms of engagement we applied Holt and Yuill's (2014) framework for collaborative technologybased interactions. Indeed, their framework captures the interactions between children with ASD in the completion of a computer-based collaborative task as well as the behaviours that support (or not) task completion. Their 'approach to task' category includes behaviours that reveal a specific interest from the student to the software but does not take into account how the players respond to each other (which is described further below). The 'withdrawal from task' category relates to behaviours that show a disconnection with the software. In order to 
observe such behaviours, all the sessions were video-recorded and coded (see further details about coding at the end of this section). Holt and Yuill (2014) did not provide specific observable criteria regarding these two categories. Consequently, we used Bartoli et al. (2013)'s framework and aligned their observable behaviours into the corresponding Holt and Yuill (2014) categories (see Appendix I).

In order to analyse the relationship between the students, we observed the non-verbal behaviours on 'active other awareness' and 'attentional other awareness' as proposed by Holt and Yuill (2014). 'Active other awareness' indicates behaviours that have an intentional, contingent relationship to partner's comment or action. 'Attentional other awareness' describes behaviours that relate to, but are not contingent on the other's action, such as accepting a partner's move without explicit acknowledgment. We used Prizant et al. (2005)'s framework to describe developmentally appropriate observable behaviours for children with ASD that aligned with the corresponding Holt and Yuill (2014) categories (see Appendix II).

\subsubsection{Enjoyment and motivation}

Regarding enjoyment, the participants completed the Scenario Experience Feedback Questionnaire (SEFQ), which has previously been used with children on the autism spectrum (Weiss et al., 2011). The SEFQ includes a 5 point likert-scale that asks about the children's enjoyment, understanding, ease of use, and sense of control while playing the game, with a maximum score of 70 (see Appendix III). The participants completed this questionnaire after the final session. Reliability was calculated with a Cronbach's alpha of 0.78 . The Cronbach's alpha coefficient ranges between 0 and 1 and an acceptable minimal reliability value is 0.7 (Nunnally, 1978).

Additionally, the students completed the Intrinsic Motivation Inventory (IMI) (Ryan \& Deci, 2000) which has also been used previously with children on the autism spectrum (Hochhauser 
et al., 2015; Weiss et al., 2011; Zancanaro et al., 2014). The IMI includes a 7 point likert-scale that asks about interest/enjoyment (maximum score $=49$ ), perceived competence (maximum score $=35)$, perceived choice $($ maximum score $=35)$ and pressure/tension (maximum score $=$ 35) while using the Body Menu (see Appendix IV). Its original validity was demonstrated by Markland and Hardy (1997). Reliability was calculated with a Cronbach's alpha of 0.93.

\subsubsection{Geography-specific knowledge}

The main purpose of this serious game focused on learning new Geography-related knowledge. To establish whether subject-specific learning took place, participants completed a pre-game questionnaire with 15 subject knowledge questions which relate to content that can be found in the game. This was completed before the first game session and repeated, with the same 15 questions plus 10 new ones, after the final game session (see Appendix V). The game also automatically saved specific data into a file from the user's matches during game play such as the numbers of correct and incorrect answers provided.

\subsubsection{Video coding}

All the sessions were video recorded with a total amount of footage of 5 hours and 25 minutes. The lead researcher and an independent coder, who was not part of the core research team, trained by coding $6 \%$ of the videos together. Then, both raters individually coded these same videos plus a further $6 \%$ of the recorded time. This provided an inter-rater check on the coding with agreement at an average of $91.6 \%$ (Active other awareness: 91\%; Approach to task: 93\%; Withdrawal from task: 91\%). Having established that the coding was highly reliable, the remaining videos were coded by the lead researcher only. 


\section{Findings}

The results are presented according to the behavioural categories described above. Some of the data obtained during this user study was missing since sometimes some participants were absent or replaced by others (see Table 2). However, when the questionnaires were filled, all the questions were answered and in any case, the main researcher was present to explain a question in case of doubts about the meaning. Thus, due to the limited number of sessions, small number of participants, and the missing data it was not appropriate to conduct statistical analyses. Instead, data are presented for each student in order to show individual responses and outcomes, as well as variability between the participants.

\subsection{Engagement and social behaviours}

The number of behaviours that described approach to task and withdrawal from task according to each session is plotted in figure 3. Figure 3 (left) reveals that participants' engagement (coded as 'approach to task') tended to decrease across the sessions.

***Include Figure 3 about here***

Figure 3 (right) shows that the withdrawal behaviours also tended to decrease across the sessions. This suggests that while participants were more 'on task' in general as the sessions progressed (they were less distracted), they were less engaged overall with the content of the game, perhaps because they found it too difficult or they became more familiar with it.

The participants did not show any behaviours categorised as attentional other awareness. The frequency of observed behaviours regarding active other awareness is plotted in Figure 4. The peaks observed on P1 appeared when P2 was absent. P1 showed the highest score while playing 
with R1 (session 2). During the session 4, P1 was playing alone against the computer [NonPlayer Character (NPC)], which explains the low rate.

***Include Figure 4 about here***

\subsubsection{Social behaviours by game mode}

Regarding the game mode (competition versus cooperation), the comparison of the participants' observed social behaviours is plotted in Figure 5 (left). The results revealed that participants were socially more engaged towards their partners when they were collaborating. However, the difference in children's engagement regarding whether they were competing or collaborating is small. This may be supported by the fact that both teams were composed of students who had different preferences, which balanced the score. Indeed, P2 and P3 said that they preferred the competition mode while $\mathrm{P} 1$ and $\mathrm{P} 4$ said they preferred the cooperative one.

Participants' comments provide insights into these individual differences, revealing either tensions or amusement between each other. For instance, although P1 shared once a feeling of being part of a team: "we are winner", tensions between P1 and P2 were observed. P1 and P2 when cooperating together sometimes put the blame on the other. P2 said during a challenge where P1 had to answer: "Oh no, he [NPC] is going to get it, how did not you get it", whereas P1 said to P2 after gambling and had lost 3 coins: "Why did you do that, you made us lose".

Regarding team 2, tensions could also be observed between P3 and P4. This could be explained by the difference of competitiveness. For instance, P3 stated that he preferred the competition mode whereas $\mathrm{P} 4$ the cooperation one. Besides being very competitive, $\mathrm{P} 3$ got excited easily and sometimes shouted his answers, which made P4 complain: "why wouldn't you stop shouting 
all in my ear" and then asking to leave the session. P4 also complained "if you stand up, it's much better. He [NPC]'s winning" when P3, during the cooperation mode, tried to play while sitting, which made the selection unstable.

Interestingly, all the complaints appeared when participants were playing in cooperation whereas the participants tended to tease each other instead during the competition mode. For instance, P2 recommended to "go for this country" when he knew that it was not possible or P1 boxed in the air towards $\mathrm{P} 2$ in order to challenge him.

\subsubsection{Social behaviours by input mode}

Regarding the input devices, although both techniques (Body Menu and mouse) were easily accepted by the participants, the mouse promoted a better engagement towards the task and a better awareness of the others (see Figure 5 right). This can be explained by the fact that the mouse is a well-known interface which is already assimilated by participants. Thus, the use of mouse might not require as much cognitive and physical effort as the Body Menu. Additionally, participants were sat while they were using the mouse, which could reduce fatigue compared with being stood up during the whole session.

In terms of social behaviour, both devices might engender frustration among the participants. For instance, P1 stated: "it was better with the mouse, sometimes it was awkward to do that [touching his head] and it was also awkward that you really had to have the other person to control cause your options showed up on them and then [P2] kept pressing no on purpose so that I kept reselecting it". On the other hand, R1 complained that it was frustrating that P1 always kept the mouse and picked the options.

$* * *$ Include Figure 5 about here*** 


\subsection{Enjoyment and motivation}

During the sessions, the participants commented their enjoyment towards the serious game. For instance, at the end of the first session, P4 came to the researcher and shook his hand saying "congratulations for the game and letting me play". P3 stated during the last session "I had fun actually" and P1 commented while playing "this game is fun, I like it a lot". These comments are in line with the results from the SEFQ which were high (Table 3). However, R1, who is the student who replaced P2 during the second session, complained about the length of the game: "I think it is a good game, it's alright, but I think it takes too long".

*** Include Table 3 about here $* * *$

The results of the IMI about the use of the Body Menu are reported in Table 3. Overall, the Body Menu was accessible since P1, P2 and P4 were able to control the technique after the first minutes of use. P3 struggled during the first session because he did not wait the threshold timer to finish for validating the selection. However, by the end of the first session he was able to control it. In addition to the fact that all the participants provided positive marks towards the Body Menu technique, P4 commented "the technique is awesome".

\subsection{Geography-specific knowledge}

$* * *$ Include Figure 6 about here*** 
The percent of correct answers achieved during game play within each of the sessions was plotted for each participant (see Figure 6). The mean learning curve across the four participants tends to increase and fits a linear model $\left(R^{2}=0.889\right)$ although, as can be seen from Figure 6 , there was some variability between the participants as would be expected. For instance, it can be observed that P1's learning curve appeared to be worse when P2 was participating. This might reflect on the affinity between participants as mentioned earlier. Nevertheless, all four participants finished at the final session scoring higher on their subject-specific knowledge than at the start of the games sessions. The percent of correct answers from the pre-test and post-test questionnaires are reported in Table 4. P4's post-test was filled by mistake by R2 which made its comparison invalid. Overall, the participants increased their Geography-specific content knowledge throughout the period of serious game play.

***Include Table 4 about here***

\section{Discussion and conclusions}

This pilot study evaluates a serious game designed by teenagers with ASD to increase Geography-related subject knowledge and encourage social interactions. Crucially, students who were involved in the game development as well as those who were not enjoyed the game, found it easy to use, and felt competent and in control during game play. They understood the game and were interested in it. These positive ratings could help to explain, at least in part, the positive learning effect shown for the targeted Geography-specific knowledge. On average, the students made more correct answers during the game as the sessions progressed. In addition, the three students from who valid data was collected gained a higher percentage score at posttest compared to pre-test for subject specific knowledge. This suggests that the students were 
motivated to engage with the content of the game and learned relevant content over a short period of time. Indeed, as their familiarity with the game increased it seemed they were more able to concentrate on the target knowledge rather than the game-playing mechanics, with concomitant benefits for learning.

Although the participants' engagement with the game decreased across the sessions, their withdrawal behaviours from the game also decreased over the same period. This suggests that as they became more familiar with the game across the sessions they did not need to put in as much effort to pay attention to the game components, hence why the frequency of behaviours categorised as 'approach to task' reduced. Concurrently, they remained focused on the task in hand ('withdrawal from task' behaviours reduced) and, as noted above, continued to provide more correct answers to the in-game questions. In addition, the game is based on a quiz-type approach, which takes advantage of visual and rote memory, and so could be a particularly beneficial approach for students with ASD (Poirier, 2008). In the context of a game that was designed by students with ASD, for students with ASD, these findings represent a very encouraging picture of the value of involving these students in a serious game design process.

Furthermore, the game was designed to involve players in pairs in order to promote social interaction between children with ASD. Overall, most participants showed high frequencies of social behaviours ('active other awareness') towards each other during game play and these social behaviours were more frequent in the cooperative compared to the competitive mode. This suggests two things: first, that the game did support children to be aware of each other and to work with each other in different ways; and second, that the cooperative mode was effective in doing what is was designed to do i.e. encourage greater collaboration between the students. While we might have expected this to be the case, it is by no means certain that this would be demonstrated empirically. For example, there are mixed findings in the literature with respect 
to whether 'collaboration by stealth' is a helpful pedagogical strategy for children with ASD (Ben-Sasson et al., 2013; Parsons, 2015).

However, this pilot study revealed two main challenges. The first one concerns the social interaction between children with ASD. Indeed, participants' attitudes varied regarding the type of session: while they complained or put the blame on the other with the cooperation mode, they tended to tease each other with the competition mode. This could reflect the fact that personal consequences follow when a cooperative partner gets something wrong or does something unexpected but there is limited control over what they do. In other words, trusting the partner is an important learning objective that may take some time to develop, especially if this is a skill that does not come naturally (Lee, 2010). Several factors can create pressure on participants apart from competitiveness, such as fatigue or simply affinity with different individuals. For instance, P1 showed higher awareness to R1 rather than P2 (see Figure 4, session 2). Then, P3 showed more engagement during competitive sessions while P4 showed more during the cooperative one, which is in line with their preferences. This highlights the importance of illustrating individual variation in responding and providing an educational context that can meet the children's differing interests and preferences (Stasolla et al., 2014; Koegel et al., 2013). Indeed, activities that meet children's interests are more likely to increase constructive engagement (Stasolla et al., 2014) and socialization between peers (Koegel et al., 2013).

The second challenge is about increasing the level of engagement with the game. Research has shown that motor development activates specific parts of the brain such as the prefrontal cortex and the cerebellum, which influence cognitive development (Diamond, 2000), and thus, learning processes (Westendorp et al., 2011). Izadi-Najafabadi et al. (2015) pointed out that children with ASD follow the same learning process as typically developing children when the 
motor learning skills are implicit, which means that the movement components are performed unconsciously by the children. By analogy, players' engagement towards the game increases when the movements are more natural (Bartoli et al., 2013; Bianchi-Berthouze, 2012). Therefore, we proposed an interface that uses body gestures, the Body Menu which was implemented with the Microsoft Kinect, as well as a more classical one with the mouse. Both interfaces were largely accepted by the participants, however, the results showed that the use of the mouse promoted better engagement among the players as well as a decrease in distraction. The mouse is, indeed, very common and does not require a high cognitive load since players are accustomed to its use. On the other hand, the Body Menu implies that the users must remain on their feet, which potentially provokes fatigue. Furthermore, since the technique is new, it requires a special cognitive attention to its execution. This difference can explain the fact that the mouse shows better results in terms of social engagement and attention towards the game. Therefore, it might be important to limit the possible distraction with simple interfaces and interaction techniques so that the participants can stay focused on the learning task.

\section{Limitations and future research}

Overall, this is a small-scale exploratory study with a small number of participants, all of whom could be considered to be high functioning. Thus, there are concomitant limitations regarding the extent to which findings can be generalised to other children with ASD. Larger-scale studies would need to be conducted to establish whether there are statistically significant gains in subject-specific learning and social engagement that can be demonstrated through playing the serious game. Furthermore, additional evidence is needed to determine the real impact on engagement and learning of body gestures as a mode of interaction compared to the use of the (much more familiar) mouse. 
Further research is also needed to carefully investigate the effect that the pairing or grouping of children has on interactions and outcomes. Our study paired children with ASD with each other, but inclusive approaches are needed to assess the preferences of children and teachers, as well as the pedagogical benefits of particular approaches to pair or group work. For example, Kasari et al., (2016) showed that children with ASD tended to work constructively with typically developing children. Therefore, future research could explore the relative strengths and benefits of inclusive Participatory Design sessions in order to analyse how peer relationships influence the design process and the developed game content.

Finally, Parsons (2016) argues that aside from the technical and learning challenges in the field of autism and technology, there is also the need to consider moving research in a more ethically and socially just direction to better reflect and celebrate the strengths and capacities of people with autism rather than continuing to focus on difficulties and impairments. In other words, research in this area should be aiming to explore what safe and comfortable online spaces could look like from the perspectives of people with ASD rather than making assumptions about this from neurotypical perspectives. The current paper is a small-scale example of the potential benefits of taking such an approach but clearly there is scope for considerable work to be done in this area, both in participatory design approaches specifically (Brosnan et al., 2016) as well as within autism research in general (Pellicano et al., 2014). 


\section{References}

American Psychiatric Association. (2013). Diagnostic and statistical manual of mental disorders (5th ed.). Washington, DC: Author

Annetta, L., Mangrum, J., Holmes, S., Collazo, K., \& Cheng, M.-T. (2009). Bridging reality to virtual reality: Investigating gender effect and student engagement on learning through video game play in an elementary school classroom. International Journal of Science Education, 31(8), pp. 1091-1113

Backlund P., Hendrix M. (2013). Educational games - Are they worth the effort? A literature survey of the effectiveness of serious games. In Proc. of Games and Virtual Worlds for Serious Applications (VS-GAMES), pp. 1-8

Bartoli L., Corradi C., Garzotto F., Valoriani M. (2013). Exploring Motion-based Touchless Games for Autistic Children's Learning. In Proc. of IDC'13, pp.102-111

Ben-Sasson, A., Lamash, L., Gal, E. (2013). To enforce or not to enforce? the use of collaborative interfaces to promote social skills in children with high functioning autism spectrum disorder. Autism, 17 (5), pp. 608-622

Benton L., Johnson H., Ashwin E., Brosnan M., Grawemeyer B. (2012). Developing IDEAS: Supporting children with autism within a participatory design team. In Proc. of CHI'12, pp. $2599-2608$

Benton, L. \& Johnson, H. (2015). Widening participation in technology design: a review of the involvement of children with special educational needs and disabilities. International Journal of Child-Computer Interaction, 3-4, 23-40

Bernardini S., Porayska-Pomsta K., Smith T.J. (2014). ECHOES: An intelligent serious game for fostering social communication in children with autism. Journal of Information Sciences, 264, pp. 41-60 
Bianchi-Berthouze, N. (2012). Understanding the Role of Body Movement in Player Engagement. Human-Computer Interaction, 28(1), 40-75.

Bossavit B., Parsons S. (2016). Designing an Educational Game for and with Teenagers with High Functioning Autism. In Proc. of PDC'16, pp. 11-20

Bossavit B., Marzo A., Ardaiz O. and Pina A. (2014). Hierarchical Menu Selection with a BodyCentered Remote Interface. Journal of Interacting with Computers, 26(5), pp. 389-402

Brosnan, M., Parsons, S., Good, J., \& Yuill, N. (2016). How can participatory design inform the design and development of innovative technologies for autistic communities? Journal of Assistive Technologies, 10(2), 115-120

Clark, D. B., Tanner-Smith, E. E., \& Killingsworth, S. S. (2016). Digital Games, Design, and Learning: A Systematic Review and Meta-Analysis. Review of Educational Research, 86(1), $79-122$

Davis M., Dautenhahn K., Powell S., Nehaniv C. (2010). Guidelines for researchers and practitioners designing software and software trials for children with autism. Journal of Assistive Technologies, 4(1), 38-48

De Freitas, S. (2006). Using games and simulations for supporting learning. Learning, Media, and Technology, 31(4), pp. 343-358

Deterding, S., Dixon, D., Khaled, R., \& Nacke, L. (2011, September). From game design elements to gamefulness: defining gamification. In Proceedings of the 15th International Academic MindTrek Conference: Envisioning Future Media Environments (pp. 9-15). New York: ACM.

Diamond, A. (2000). Close interrelation of motor development and cognitive development and of the cerebellum and prefrontal cortex. Child Development, 71(1), 44-56. 
Durkin K., Boyle J., Hunter S., \& Conti-Ramsden G. (2013). Video games for children and adolescents with special educational needs. Journal of Psychology, 221(2), 79-89

Frauenberger C., Good J., Alcorn A., Pain H. (2013). Conversing through and about technologies: Design critique as an opportunity to engage children with autism and broaden research(er) perspectives. International Journal of Child-Computer Interaction, 1(2), 38-49

Girard, C., Ecalle, J., \& Magnan, a. (2013). Serious games as new educational tools: How effective are they? A meta-analysis of recent studies. Journal of Computer Assisted Learning, $29,207-219$

Granic, I., Lobel, A., Engels, R. (2014). The benefits of playing video games. American Psychologist, 69(1), 66-78

Grynszpan, O., Weiss, P. L., Perez-Diaz, F., \& Gal, E. (2014). Innovative technology-based interventions for autism spectrum disorders: A meta-analysis. Autism, 18(4), 346-361

Holt S., Yuill N. (2014). Facilitating other-awareness in low-functioning children with autism and typically-developing preschoolers using dual-control technology. Journal of Autism and Developmental Disorders, 44(1), 236-248.

Hochhauser, M., Gal, E., Weiss, P.L. (2015). Negotiation Strategy Video Modeling Training for Adolescents with Autism Spectrum Disorder: A Usability Study. International Journal of Human-Computer Interaction, 31 (7), pp. 472-480.

Izadi-Najafabadi, S., Mirzakhani-Araghi, N., Miri-Lavasani, N., Nejati, V., Pashazadeh-Azari, Z. (2015). Implicit and explicit motor learning: Application to children with Autism Spectrum Disorder (ASD). Research in Developmental Disabilities, 47, pp. 284-296 
Jordan, R. (2005). Autistic spectrum disorders. Chapter in B. Norwich and A. Lewis (Eds) (2005) Special teaching for special children?: pedagogies for inclusion. Maidenhead, England: McGraw-Hill International (pp.110-122).

Kapp, K. M. (2012). The gamification of learning and instruction: Game-based methods and strategies for training and education. San Francisco, CA: Pfeifer

Kasari, C., Dean, M., Kretzmann, M., Shih, W., Orlich, F., Whitney, R., Landa, R., Lord, C., King, B. (2016). Children with autism spectrum disorder and social skills groups at school: a randomized trial comparing intervention approach and peer composition. Journal of Child Psychology and Psychiatry and Allied Disciplines, 57(2), 171-179

Knight V., McKissick B.R., Saunders A. (2013). A review of technology-based interventions to teach academic skills to students with autism spectrum disorder. Journal of Autism and Developmental Disorders, 43(11), 2628-2648

Koegel, R., Kim, S., Koegel, L., Schwartzman, B. (2013). Improving Socialization for High School Students with ASD by Using their Preferred Interests. Journal of Autism and Developmental Disorders.; 43(9), 2121-2134

Latham S.O., Stockman I.J. (2014). Effect of Augmented Sensorimotor Input on Learning Verbal and Nonverbal Tasks Among Children with Autism Spectrum Disorders. Journal of autism and developmental disorders, 44(6), 1288-1302

Lavelle T. A., Weinstein M. C., Newhouse J. P., Munir K., Kuhlthau K. A., Prosser L. A. (2014). Economic burden of childhood autism spectrum disorders. Pediatrics, 133(3), 520-529 Lee, K. (2010). 'Understanding the Friendship Processes of Individuals with Asperger's Syndrome: A Phenomenological Study of Reflective College Experiences." PhD dissertation, The College of William and Mary. ProQuest LLC 
Malinverni L., Mora-Guiard J., Padillo V., Valero L, Hervás A., and Pares N. (2016). An inclusive design approach for developing video games for children with Autism Spectrum Disorder. Computers in Human Behavior. http://dx.doi.org/10.1016/j.chb.2016.01.018

Markland, D., \& Hardy, L. (1997). On the factorial and construct validity of the intrinsic motivation inventory: Conceptual and operational concerns. Research Quarterly for Exercise and Sport, 68, 20-32. doi:10.1080/02701367.1997.10608863

Millen L., Cobb S., Patel H. (2011). Participatory design approach with children with autism. International Journal on Disability and Human Development, 10(4), 289-294

Molins-Ruano P., Sevilla C., Santini S., Haya P.A., Rodríguez P., Sacha G.M. (2014). Designing videogames to improve students' motivation. Journal of Computers in Human Behavior, 31, pp. 571-579

Montes G., Halterman J. S. (2008). Association of childhood autism spectrum disorders and loss of family income. Pediatrics, 121(4), e821-e826

Nunnally, J. C. (1978). Psychometric theory (2nd ed.). New York: McGraw-Hill

Parsons, S., Millen, L., Garib-Penna, S. \& Cobb, S. (2011) Participatory design in the development of innovative technologies for children and young people on the autism spectrum: the COSPATIAL project. Journal of Assistive Technologies, 5(1), 29-34.

Parsons S., Cobb S. (2014). Reflections on the role of the 'users': challenges in a multidisciplinary context of learner-centred design for children on the autism spectrum. International Journal of Research \& Method in Education, 37(4), 421-441.

Parsons, S. (2015) Learning to work together: designing a multi-user virtual reality game for social collaboration and perspective-taking for children with autism. International Journal of Child-Computer Interaction, 6, pp. 28-38 
Parsons, S. (2016). Authenticity in Virtual Reality for assessment and intervention in autism: A conceptual review. Educational Research Review, 19, 138-157

Pellicano, E., Dinsmore, A., \& Charman, T. (2014). What should autism research focus upon? Community views and priorities from the United Kingdom. Autism, 18, 756-770

Pennington, R. C. (2010). Computer-assisted instruction for teaching academic skills to students with autism spectrum disorders: A review of literature. Focus on Autism and Other Developmental Disabilities, 25(4), 239-248

Poirier, M. (2008). Working memory and immediate memory in autism spectrum disorders. Memory in Autism, pp. 231-248

Ploog, B. O., Scharf, A., Nelson, D., \& Brooks, P. J. (2013). Use of computer-assisted technologies (CAT) to enhance social, communicative, and language development in children with autism spectrum disorders. Journal of Autism and Developmental Disorders, 43(2), 301322

Prizant, B.,Wetherby, A., Rubin, E., Laurent, A., and Rydell, P. (2005). The SCERTS ${ }^{\mathrm{TM}}$ Model: A Comprehensive Educational Approach for Children with Autism Spectrum Disorders. Brookes Publishing Company, Baltimore, MD, USA

Ravet, J. (2011). Inclusive/exclusive? Contradictory perspectives on autism and inclusion: the case for an integrative position. International Journal of Inclusive Education, 15(6), 667-682.

Ryan, R. M., \& Deci, E. L. (2000). Self-determination theory and the facilitation of intrinsic motivation, social development, and well being. American Psychologist, 55,68-78

Serret, S., Hun, S., Iakimova, G., Lozada, J., Anastassova, M., Santos, A., Vesperini, S., Askenazy, F. (2014). Facing the challenge of teaching emotions to individuals with low-and high-functioning autism using a new Serious game: a pilot study. Molecular Autism, 5, 37. 
Stasolla, F., Damiani, R., \& Caffo, A.O. (2014). Promoting constructive engagement by two boys with autism spectrum disorders and high functioning through behavioral interventions. Research in Autism Spectrum Disorders, 8, 376-380

Wass S.V., Porayska-Pomsta K. (2014) The uses of cognitive training technologies in the treatment of autism spectrum disorders Autism, 18(8), 851-871

Weiss, P.L., Gal, E., Zancanaro, M., Giusti, L., Cobb, S., Millen, L., Hawkins, T., Glover, T., Sanassy, D., Eden, S. (2011). Usability of technology supported social competence training for children on the Autism Spectrum. In proc. of Virtual Rehabilitation (ICVR), pp.1-8

Westendorp, M., Hartman, E., Houwen, S., Smith, J., \& Visscher, C. (2011). The relationship between gross motor skills and academic achievement in children with learning disabilities. Research in Developmental Disabilities, 32(6), 2773-2779.

Whyte E.M., Smyth J.M., Scherf K.S. (2015). Designing Serious Game Interventions for Individuals with Autism. Journal of Autism and Developmental Disorders, 45(12), 3820-31.

Wrzesien M., Raya M.A. (2010) Learning in serious virtual worlds: evaluation of learning effectiveness and appeal to students in the E-Junior project. Computers \& Education 55, pp. $178-187$

Zancanaro, M., Giusti, L., Bauminger-Zviely, N., Eden, S., Gal, E., \& Weiss, P. L. (2014). NoProblem! A collaborative interface for teaching conversation skills to children with high functioning autism spectrum disorder. Playful User Interfaces, Gaming Media and Social Effects, pp. 209-224. doi:10.1007/978-981-4560-96-2_10 


\section{Figures captions}

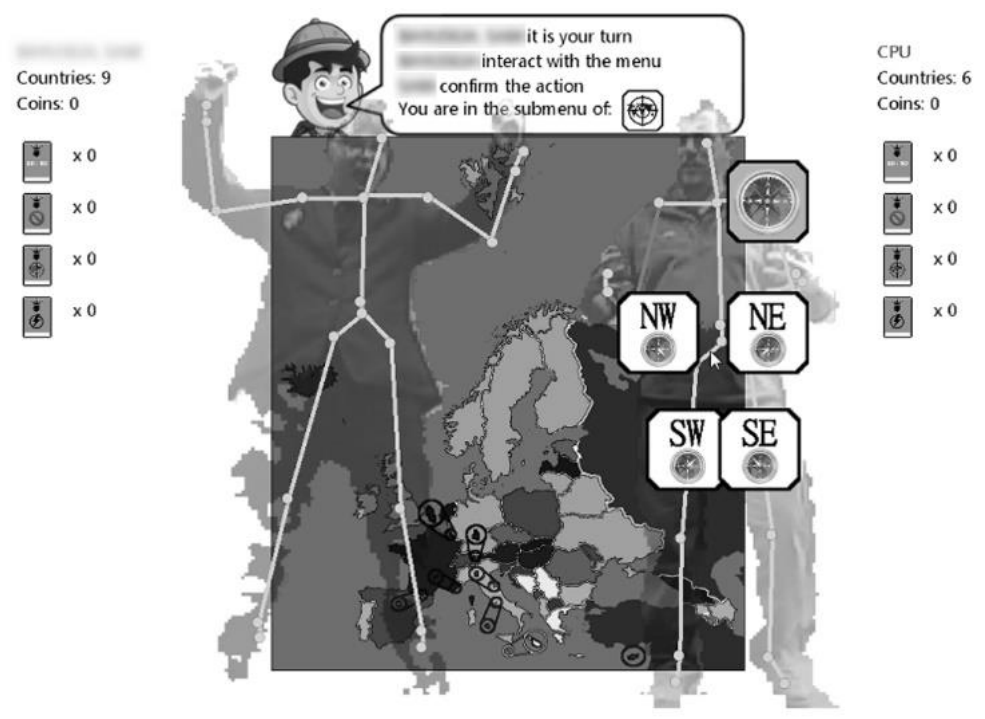

Figure 1: Interface of the game; the map is displayed on the middle of the screen and users' inventory on the borders

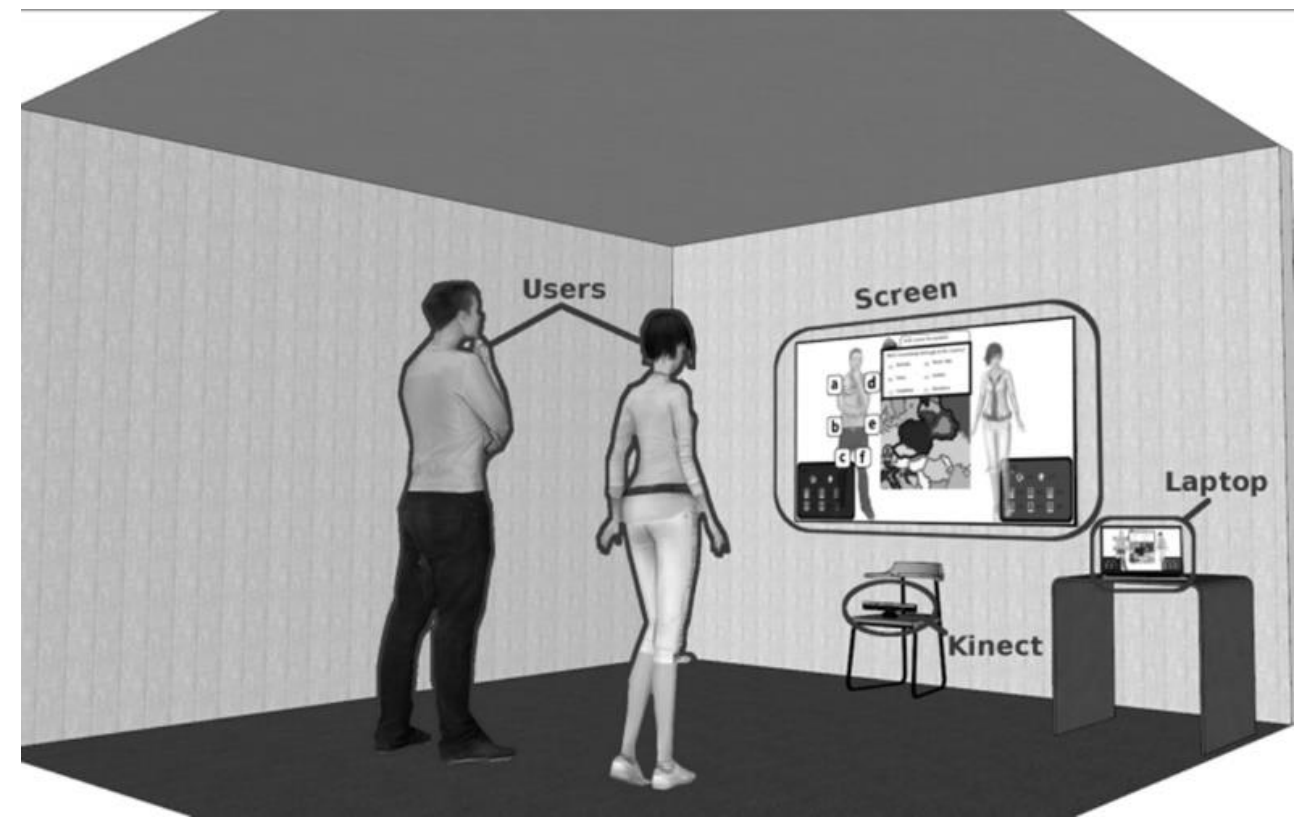

Figure 2: Game setting that includes a screen, a laptop, the Kinect and two players 


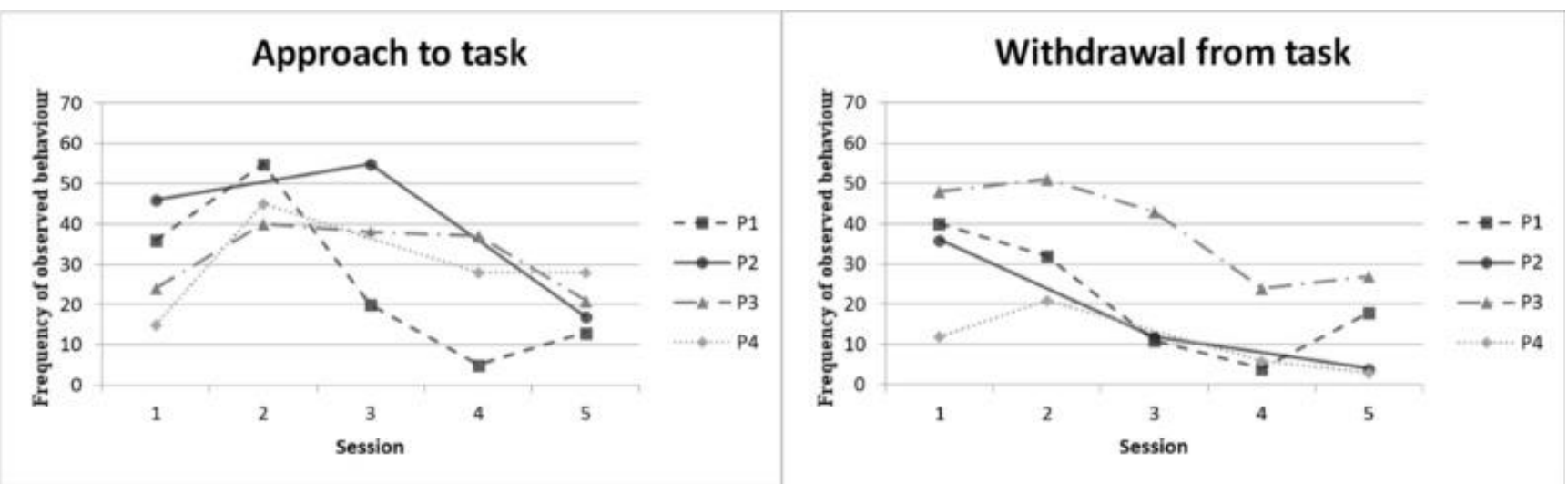

Figure 3: frequency of the observed behaviours related to approach to task and withdrawal from task for each user across the 5 sessions

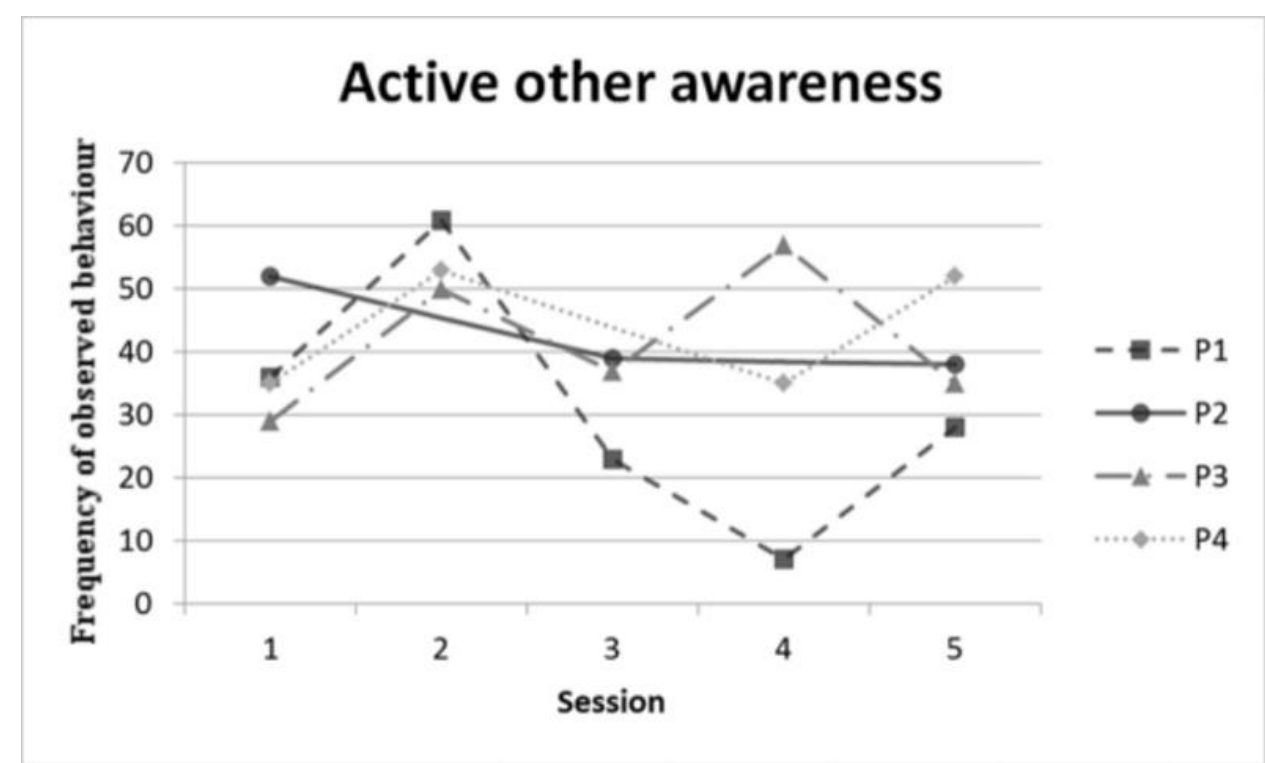

Figure 4: frequency of the observed behaviours related to other awareness for each user across the 5 sessions 


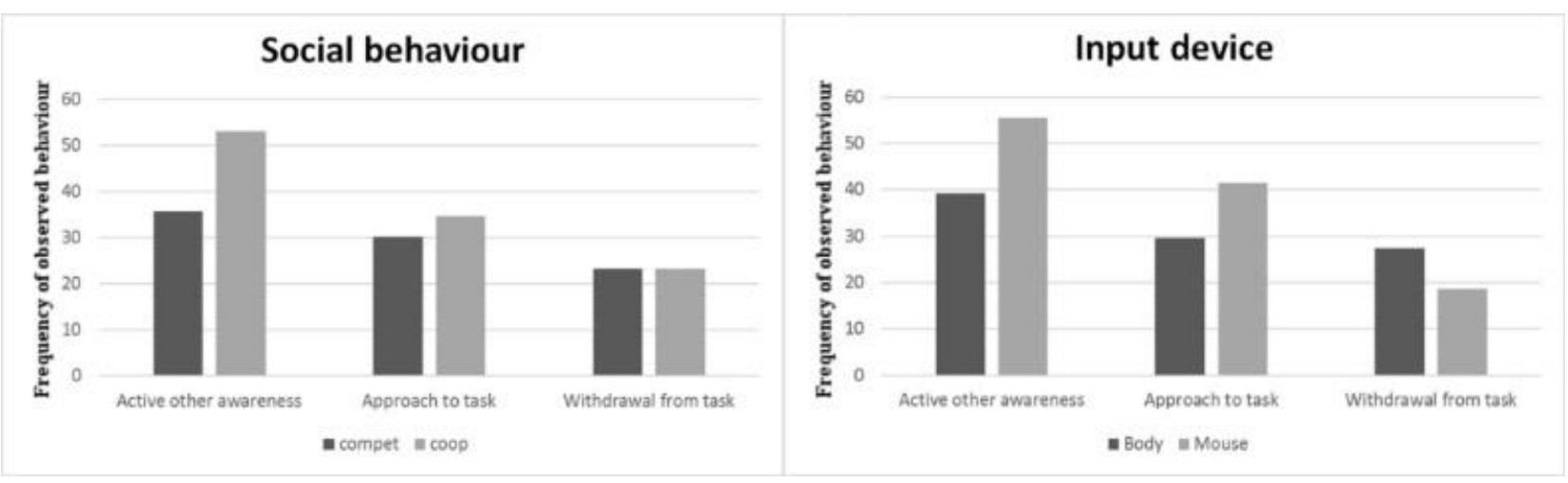

Figure 5: comparison of the frequency of observed behaviour (other-awareness and engagement criteria) between the use of competition and cooperation modes (on the left) and between the use of Body Menu and mouse (on the right).

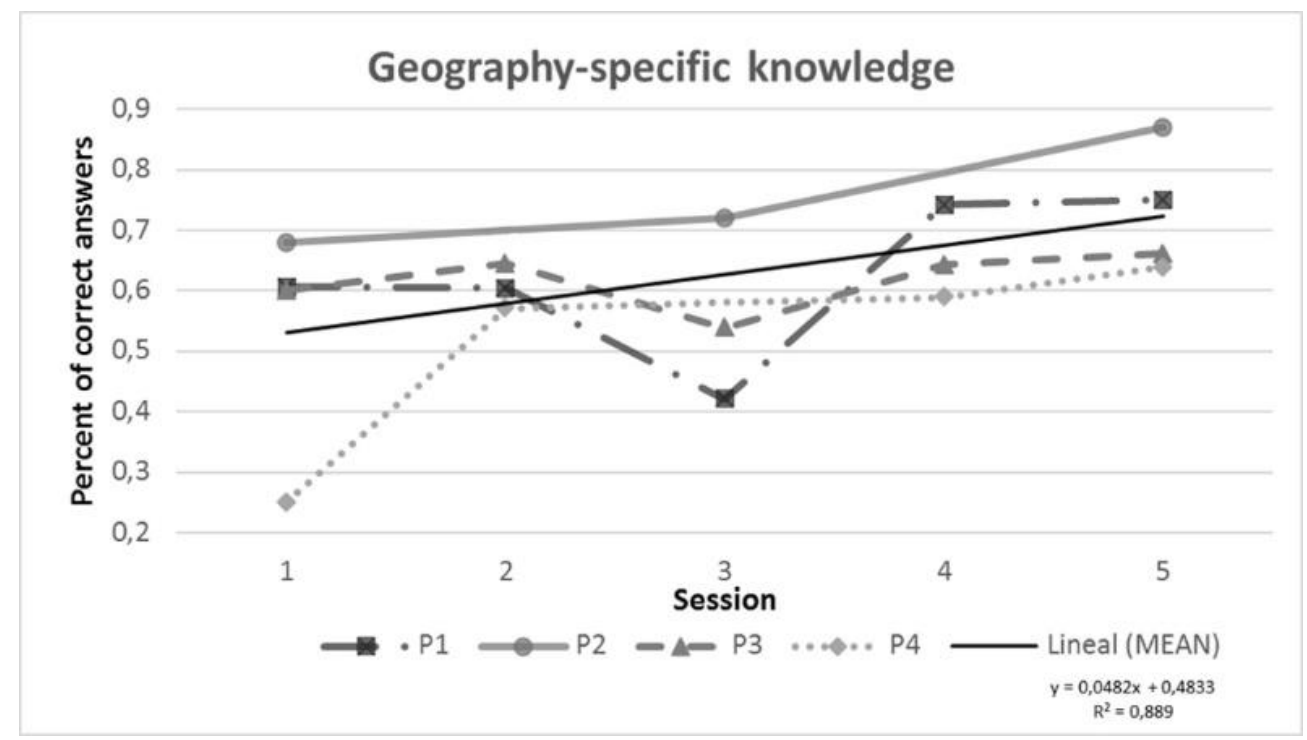

Figure 6: ratio of correct answers across the sessions 